\title{
GREAT: 10 year survival of patients with suspected acute myocardial infarction in a randomised comparison of prehospital and hospital thrombolysis
}

\section{J Rawles}

Heart 2003;89:563-564

$\mathrm{T}$ he Grampian region early anistreplase trial (GREAT) assessed the feasibility, safety, and efficacy of prehospital thrombolysis given by general practitioners. ${ }^{1}$ This treatment was shown to be feasible and safe in their hands, and at one year a halving of mortality was reported $(p=0.007){ }^{2}$ Seven other small randomised trials comparing prehospital with hospital thrombolysis have been published, and although none showed significant benefit at one month, meta-analysis has confirmed the value of prehospital thrombolysis. ${ }^{3}$

Standard 6 of the National Service Framework for coronary heart disease requires that thrombolysis should be given within 60 minutes of calling for professional help. ${ }^{4}$ Since GREAT has been influential in informing policy decisions and formulating this target, the 10 year results are presented in this paper.

\section{PATIENTS AND METHODS}

The trial and the results at three months were fully described in 1992. ${ }^{1}$ Twenty nine rural practices in Grampian participated, and these were located 26-100 km (mean $58 \mathrm{~km}$ ) by road from Aberdeen where all patients were admitted to hospital. Three hundred and eleven patients with suspected acute myocardial infarction seen within four hours of symptom onset and without contraindications to thrombolytic treatment were recruited between December 1988 and 31 December 1991: 163 patients were randomly allocated to the "prehospital" group and received anistreplase 30 units intravenously from their general practitioners, followed by placebo after admission to hospital; 148 patients in the "hospital" group received placebo prehospital followed by anistreplase in hospital. The median time intervals from onset of symptoms to administration of anistreplase were 1.75 and 4 hours in prehospital and hospital groups, respectively.

General practitioners recorded an ECG but were not required to interpret it for trial entry; 180 patients had ST elevation or bundle branch block (BBB) on either the prehospital recording or the first recording in hospital. All patients were flagged with the Scottish Registry Office and their deaths notified to us. Follow up data has been censored at the 10th anniversary of trial entry.

\section{RESULTS}

In 10 years there were 142 deaths, $73 / 163$ in the prehospital group, and 69/148 in the hospital group. Survival curves for prehospital and hospital groups are shown in fig 1 . The curves diverge for the first two years, and then converge.

Improved survival with prehospital thrombolysis was confined to those with ST elevation or BBB, and fig 2 compares survival curves for prehospital and hospital groups in the 180 patients with these abnormalities.

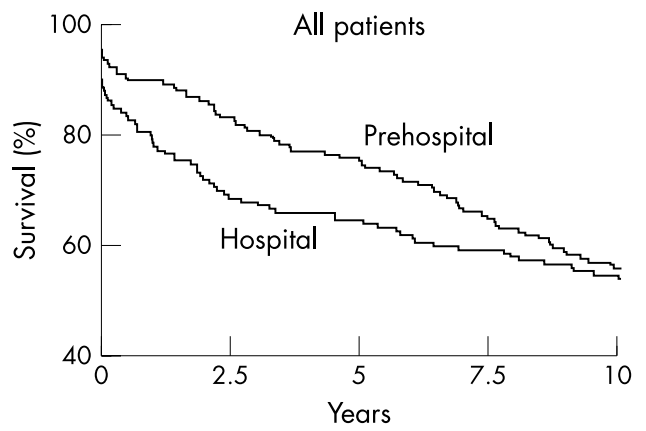

Figure 1 Survival curves for 311 patients receiving thrombolysis prehospital or in hospital.

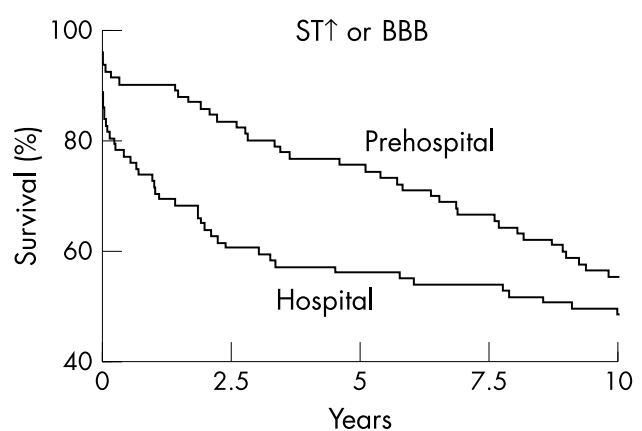

Figure 2 Survival curves for 180 patients with ST elevation or bundle branch block (BBB) on the presenting ECG, and receiving thrombolysis prehospital or in hospital.

\section{DISCUSSION}

All discussion of GREAT must be prefaced with the caveat that the trial was small, the confidence intervals large, and the conclusions necessarily tentative.

Ten year follow up of GREAT has reaffirmed the value of prehospital thrombolysis that was apparent when the first results of the trial were published in 1992. In spite of the late convergence of the survival curves, patients in the prehospital group enjoyed an appreciable survival advantage compared with those in the hospital group. The area between the survival curves in fig 1 is equivalent to 0.9 (95\% confidence interval (CI) -0.1 to $1.9 ; 7.4 \vee 6.5$ ) years, and represents the additional survival enjoyed on average by each of the patients in the prehospital group compared with those in the hospital group during 10 years' follow up.

Entry into GREAT did not require electrocardiographic confirmation of the diagnosis, although an ECG was recorded. Nowadays, the presence of ST elevation or bundle branch block on the presenting ECG is generally considered a prerequisite for thrombolytic treatment. Our results endorse this policy, showing that the benefits of prehospital thrombolysis 
are confined to those with these ECG abnormalities. In the subset of GREAT patients who met the current ECG criteria for thrombolysis, the average survival advantage following prehospital thrombolysis was 1.6 (95\% CI 0.5 to $2.6 ; 7.4 v 5.9$ ) years, equivalent to a $16 \%$ average difference in mortality maintained over 10 years. It is possible that the extended benefit seen in the first two years would have been maintained and enhanced if prehospital thrombolysis had been complemented with an aggressive surgical reperfusion strategy.

Prehospital thrombolysis continues to be practised in Grampian, ${ }^{6}$ and there has been some expansion of its use in rural Scotland. ${ }^{7}$ In England and Wales only a handful of general practitioners are known to be using this treatment, and in pilot projects in two ambulance trusts only a few patients have been treated by paramedics. Implementation of prehospital thrombolysis is 10 years overdue.

\section{ACKNOWLEDGEMENTS}

The names of the general practitioners who participated so magnanimously are given in reference 1 . The trial was supported by SmithKline Beecham. Long term follow up was funded by a grant from the Acute Healthcare Research Committee of the Scottish Home and Health Department.
Correspondence to: Dr J Rawles, Brunnion Minor, Lelant Downs, Hayle TR27 6NT, UK; john.rawles@btinternet.com

Accepted 20 November 2002

\section{REFERENCES}

1 GREAT Group. Feasibility, safety, and efficacy of domiciliary thrombolysis by general practitioners. BM 1992;305:548-53.

2 Rawles J, on behalf of the GREAT Group. Halving of 1-year mortality from acute myocardial infarction by domiciliary thrombolysis in the Grampian region early anistreplase trial (GREAT). J Am Coll Cardiol 1994;23:1-5.

3 Morrison LJ, Verbeek PR, McDonald AC, et al. Mortality and prehospital thrombolysis for acute myocardial infarction. A meta-analysis. JAMA 2000;283:2686-92

4 Department of Health. National service framework for coronary heart disease. London: Department of Health, 2000. www.doh.gov.uk/nsf/ coronary.htm

5 Loubeyre $C$, Lefevre $T$, Louvard $Y$, et al. Outcome after combined reperfusion therapy for acute myocardial infarction, combining pre-hospital thrombolysis with immediate percutaneous coronary intervention and stent. Eur Heart J 2001;22:1 128-35.

6 Rawles J, Sinclair C, Jennings K, et al. Audit of prehospital thrombolysis by general practitioners in peripheral practices in Grampian. Heart 1998;80:231-4

7 Rawles JM, Ritchie LD. Thrombolysis in peripheral general practices in Scotland: another rule of halves. Health Bulletin 1999;57:10-16.

\section{IMAGES IN CARDIOLOGY}

\section{Management of complex, two chamber false aneurysm by thrombin injections}

- alse aneurysms develop at the puncture site in up to $6 \%$ of - percutaneous cardiovascular procedures. Previous management of false aneurysms consisted of surgical repair or compression therapy. Drawbacks of surgery are its invasiveness, compression therapy pain, and prolonged compression bandages. An alternative to both is selective injection of thrombin into the false aneurysm. However, its effectiveness in complex, double chamber aneurysms in patients treated with enoxaparin, aspirin and clopidogrel, and abciximab is not clear as yet.

After an acute invasive procedure using a 6 French sheath in a 79 year old man with acute myocardial infarction, a complex two chamber false aneurysm occurred. The patient was not suitable for compression therapy because of intense pain, despite local lidocaine injections and systemic morphine ( $15 \mathrm{mg}$ ). The surgeons refused to operate on the patient because of systemic anticoagulation (enoxaparin subcutaneously, $1.0 \mathrm{ml}$ twice per day) and treatment with aspirin

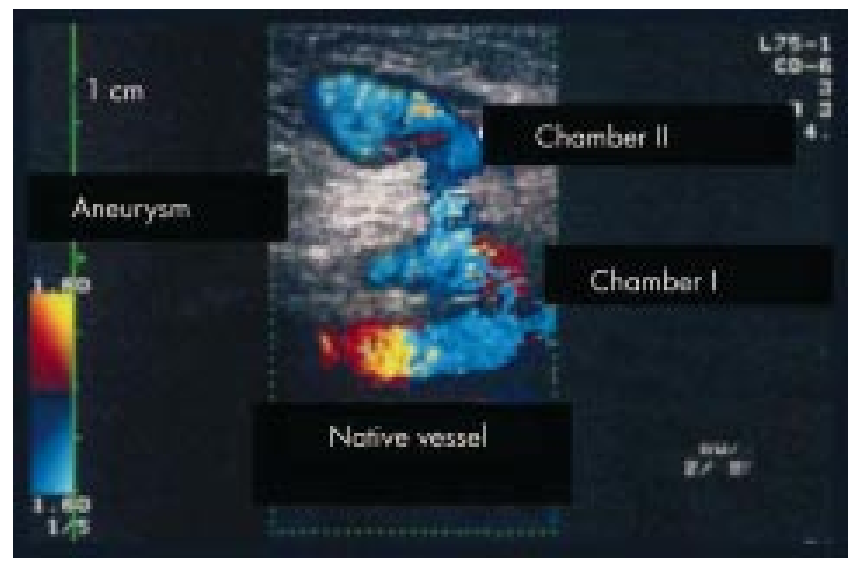

( $500 \mathrm{mg}$ initial dose, followed by $100 \mathrm{mg} /$ day), clopidogrel (300 mg initial dose, followed by $75 \mathrm{mg} /$ day) and weight adjusted abciximab.

To induce clot formation, "chamber I" was punctured percutaneously under ultrasound guidance with a 20 gauge needle. Brief aspiration and re-injection of blood confirmed the correct position of the needle. After injection of $550 \mathrm{U}$ of diluted thrombin solution (GenTrac, Middleton, Wisconsin, USA) thromboses of both chambers occurred. The patient received a cool pack for two hours. No complications occurred until hospital discharge.

Therefore, thrombin injections are effective for management of false aneurysms, even in patients with a complex anatomy and treatment with systemic anticoagulation and high dose anti-aggregation therapy.

G Görge

T Kunz g.gorge@mx.uni-saarland.de

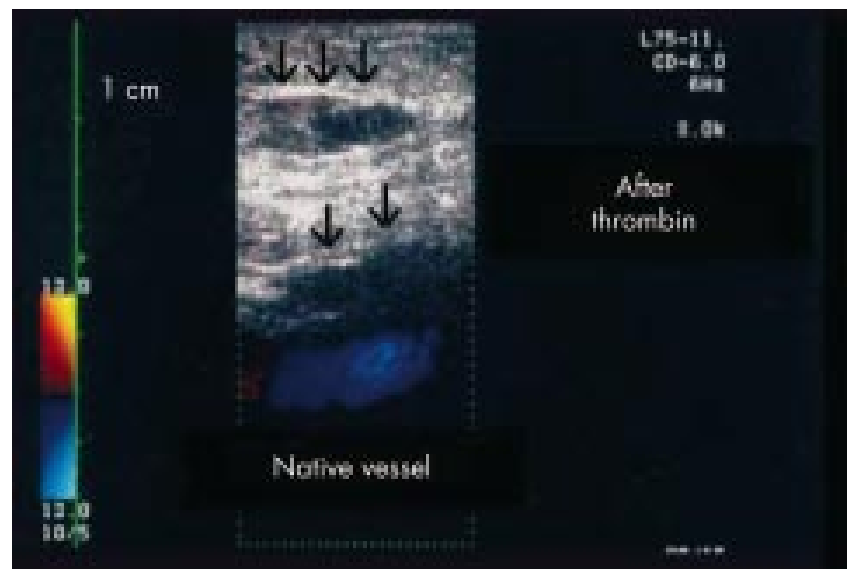

